\title{
A Comparison of Major Environmental Justice Screening and Mapping Tools
}

\author{
Lakshika Nishadhi Kuruppuarachchi \\ Department of Mechanical, Industrial and Manufacturing Engineering \\ The University of Toledo, 2801 W. Bancroft Street, Toledo, OH, 43606, USA \\ Tel: 419-699-0424Ｅ-mail: Lakshika.Kuruppuarachchi@ rockets.utoledo.edu
}

Ashok Kumar (Corresponding author)

Department of Civil Engineering, The University of Toledo

2801 W. Bancroft Street, Toledo, OH 43606, USA

Tel:419-530-8136Ｅ-mail: Ashok.Kumar@utoledo.edu

\begin{abstract}
Matthew Franchetti
Department of Mechanical, Industrial and Manufacturing Engineering The University of Toledo, 2801 W. Bancroft Street, Toledo, OH, 43606, USA

Tel:419-530-8051Ｅ-mail: matthew.franchetti@utoledo.edu
\end{abstract}

Received: February 17, 2017 Accepted: March 4, 2017

doi:10.5296/emsd.v6i1.10914 URL: https://doi.org/10.5296/emsd.v6i1.10914

\begin{abstract}
The concept of Environmental Justice (EJ) has evolved in United Sates for more than 30 years. Since then most empirical studies have shown that low-income and minority neighborhoods are disproportionately exposed to environmental hazards. Across the world, communities are struggling to protect their land, air, water, forests, and their livelihoods from damaging projects and activities with heavy environmental and social impacts. A Number of tools already exist to identify and map those areas with potential environmental justice concerns. This paper presents a comparison of the three major EJ tools; EJSCREEN (version 2016), CalEnviroScreen 2.0, EJ Atlas and their methodologies. There are some common parameters across these tools in presenting Environmental Justice and in identifying environmentally burdened communities, socially burdened communities, or both.
\end{abstract}


Environmental burdens can include any environmental pollutant, hazard or disadvantage that compromises the health of a community. The tools are expected to help in understanding and studying the distribution of environmental benefits and burdens, decision making for disadvantaged communities in certain areas and in setting up environmental policies and planning.

Keywords: Environmental Justice, Environmental Protection Agency, demographic, EJSCREEN, CalEnviroScreen, EJ Atlas

\section{Introduction}

Communities around the world have complained about exploitation of land uses for decades. Studies show that in 1982, there was a large protest (Bullard \& Lewis, 1996) against a PCB (Polychlorinated biphenyl) landfill in Afton, Warren County, North Carolina where $84 \%$ of the population were African American and was the poorest county in North Carolina at that time. The state of North Carolina had designated a site in this small African American community, out of a number of potential sites for dumping these toxic wastes. The protestors had argued that mostly this African American community was selected because it was minority and poor. Followed by the Warren County protest, people in poor minority communities created groups to fight environmental burdens on them. As a result of all these protests and complaints, The Federal Actions to address EJ in the minority population and low-income populations was issued by President William J. Clinton in 1994 (U.S. EPA, 2015).

EJ is not universally defined. Several definitions were introduced based on the perspective, time, and place by different organizations and authorities. Four definitions of EJ is listed below.

U.S. Environment Protection Agency defines EJ as "The fair treatment and meaningful involvement of all people with respect to development, implementation, and enforcement of environmental laws, regulations, and policies" (U.S. EPA, 2016). Fair treatment means (Taylor, et al., 2007) that no population is forced to bears a disproportionate share of negative environmental consequences because of the influence of any policy or regulation. These influences include industrial, municipal, and commercial operations or execution of federal, state, and local laws, regulations and policies resulting any air, land and water pollution and other environmental consequences. These meaningful involvements mean the ability of effective access to decision makers in all communities and making informed decisions, where they can take positive actions to enhance EJ for themselves.

EJ (Asian Pacific Environmental Network, 2002) is "The right to a decent, safe quality of life for people of all races, incomes, and cultures in the environments where we live, work, play, learn and pray". In addition, EJ highlights responsibilities, independent practices, unbiased treatments and self-determination by prioritizing public moral over profit, cooperation over competition and protective approaches over unacceptable risks. EJ provides an outline for communities for understanding why environmental racism happens and how it continues.

The state of Maryland defines EJ (The State of Maryland, 2016) as "Equal protection from 
environmental and public health hazards for all people regardless of race, income, culture, and social class". Additionally, EJ means that no group of people including racial, ethnic or socioeconomic groups should bear a disproportionate share of the negative environmental consequences resulting from industrial, land-use planning and zoning, municipal and commercial operations or the execution of federal, state, local and municipal program and policies.

U.S. Department of Agriculture explains EJ (U.S. Department of Agriculture, 2012) as: "To the greatest extent practicable and permitted by law, all populations are provided the opportunity to comment before decisions are rendered on proposed Federal actions". Furthermore, the principles of EJ require that populations are allowed to share in the benefits of but neither excluded nor affected in a disproportionately high and adverse manner by, government programs and activities affecting human health or the environment.

An internet search was carried out for the available EJ tools. Three major EJ tools; EJSCREEN (version 2016), CalEnviroScreen 2.0, and EJ Atlas were selected for discussion and possible use by the readers for their projects.

\section{EJSCREEN}

EJSCREEN is an environmental justice screening and mapping tool developed by the EPA and was first released to the public in the year 2015 replacing the tool EJView. The tool consists of a nationally reliable dataset and an approach for combining environmental and demographic indicators. In 2016, the second version of the tool was released to the public with the most recent data and with several new features. The tool provides demographic and environmental information for the user selected geographic areas. EJSCREEN combines environmental and demographic information into EJ Indexes. For a selected geographic area, the tool will generate an EJ Index based on the environmental factor and the two demographic factors; low-income population and minority population. An EJ Index represents a single environmental indicator. The twelve environmental indicators (U.S. EPA, 2014) used in EJSCREEN by U.S. EPA are described as follows.

\subsection{Environmental Indicators}

1. Particulate Matter (PM2.5 level) in the air- micrograms per cubic meter $(\mu \mathrm{g} / \mathrm{m} 3)$ annual average.

2. Ozone - Ozone summer seasonal average of daily maximum 8-hour concentration in air in parts per billion (ppb).

3. Traffic Proximity and Volume - Count of vehicles per day (average annual daily traffic) at major roads within 500 meters (or nearest one beyond $500 \mathrm{~m}$ ), divided by distance in kilometers $(\mathrm{km})$.

4. Lead Paint Indicator - Percent of housing units built before 1960, as an indicator of potential exposure to lead paint.

5. Proximity National Priority List Sites (NPL) - Count of proposed and listed NPL sites within $5 \mathrm{~km}$ (or nearest one beyond $5 \mathrm{~km}$ ), each divided by distance in $\mathrm{km}$ The NPL is the 


\section{Macrothink}

list of hazardous waste sites in the United States eligible for long-term remedial action (cleanup) financed under the federal Superfund program

6. Proximity to Risk Management Plan Facilities (RMP) - Count of RMP (potential chemical accident management plan) facilities within $5 \mathrm{~km}$ (or nearest one beyond $5 \mathrm{~km}$ ), each divided by distance in $\mathrm{km}$

7. Proximity to Treatment Storage and Disposal Facilities (TSDF) - Count of TSDF (hazardous waste management facilities) within $5 \mathrm{~km}$ (or nearest one beyond $5 \mathrm{~km}$ ), each divided by the distance in $\mathrm{km}$.

8. Proximity to Major Direct Dischargers to Water - Count of National Pollution Elimination Discharge System (NPDES) major direct water discharger facilities within $5 \mathrm{~km}$ (or nearest one beyond $5 \mathrm{~km}$ ), each divided by the distance in $\mathrm{km}$.

9. National Air Toxic Assessment (NATA) Diesel PM - Diesel PM level in the air, $\mu \mathrm{g} / \mathrm{m} 3$.

10. NATA Air Toxic Cancer Risk - Excess lifetime cancer risk from inhalation of air toxics

11. NATA Respiratory Hazard Index - Ratio of exposure concentration to health-based reference concentration.

12. NATA Neurological Hazard Index - Ratio of exposure concentration to health-based reference concentration.

The twelve environmental indicators considered in EJSCREEN can be grouped into three categories as shown in Figure 1. Environmental indicators in the category of proximity may have a high combination of environmental burdens and vulnerable populations-not actual exposure or risk.

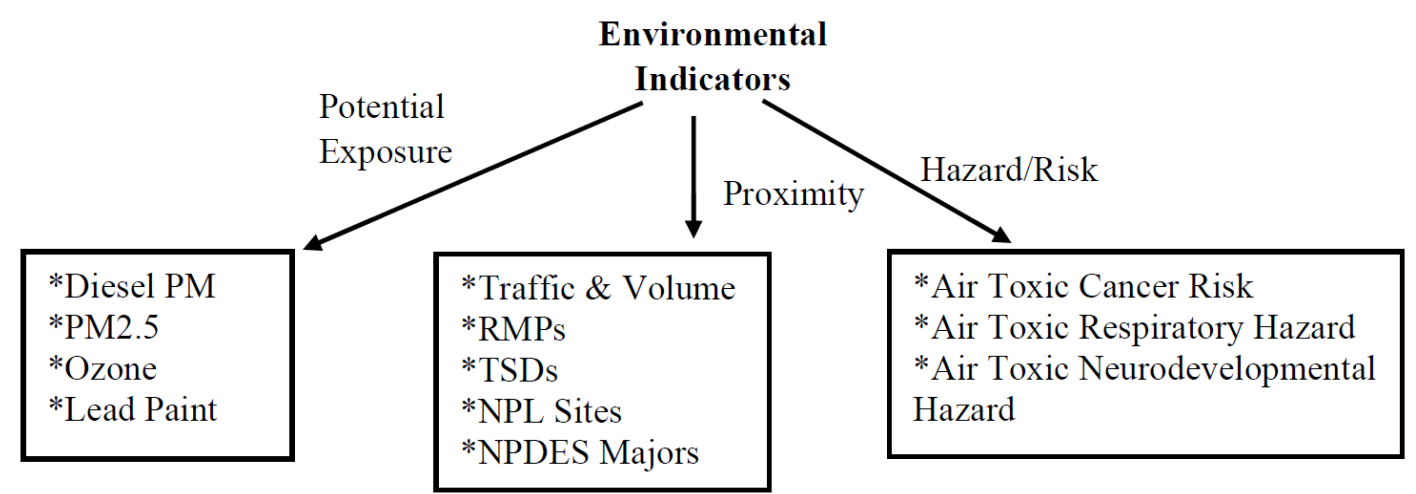

Figure 1. Major Groups of Environmental Indicators used in EJSCREEN

\subsection{Demographic Index}

The Demographic Index in EJSCREEN is a combination of percent low-income and percent minority. For each Census block group, these two numbers are simply averaged together. A census block (U.S. Census Bureau, 2011) is the smallest geographic unit, which gives the basic demographic data delineated by the United States Census Bureau for tabulation of 100-percent data once every ten years. The formula is as follows, calculated from the Census Bureau's American Community Survey 2008-2012.

The mathematical formula for finding the Demographic Index. 
Demographic Index $=(\%$ minority $+\%$ low-income $) / 2$

\subsection{EJ Index}

EPA uses the following formula in calculating the EJ Index for a selected area. It will generate a single EJ Index for each environmental variable. The EJ standard report presents the EJ Indexes as a percentile. It compares the EJ Index of a selected area with the state, EPA region, and the United States and finally gives three percentile values, which are easier for the user in understanding the results relatively.

$$
\text { EJ Index }=\text { EI } *(\text { DIB }- \text { DIUS }) * \text { Population count for block group }
$$

where,

$\mathrm{EI}=$ Environmental Indicator

DIB = Demographic Index for Block Group

DIUS $=$ Demographic Index for US

The EJ Index raw value itself is not reported in EJSCREEN reports. It is reported in percentile terms, to make the results easier to interpret. For calculated EJ Index raw value using the formula, it is clear that the EJ Index value can be a positive or negative number, depending on the DIB and DIUS values. A positive number occurs where the local demographic index is above the U.S. average. This implies the location adds to any excess in environmental indicator values among the specified populations (minority and low income) nationwide. A negative value occurs where the local demographic index is below the U.S. average, and it means the location offsets the other locations, reducing any excess in nationwide average environmental indicator values among minority and low-income populations relative to others. Most EJSCREEN users will not work directly with EJ Index raw values, however, positive raw values for an EJ Index will be presented as higher percentiles and negative raw values will appear as lower percentiles.

\subsection{EJSCREEN Results}

EJSCREEN tool has census block group resolution and provides a number of capabilities, including color-coded mapping, the ability to generate a standard report for a selected area, and comparisons showing how a selected area compares to the relevant state, EPA region, or the nation as a whole map. As an example, Figure 2 presents the EJ Index for PM 2.5 for the city of Columbus, Ohio. For a user-specified point, address, geographic coordinates or a location the map will focus on a point and provide a 1-mile buffer as the default. Buffers can be drawn up to 10 miles around a point, line or polygon.

The standard EJSCREEN report contains a table comparing the EJ Indexes in state, region and nationwide for the twelve environmental variables. Table 1 illustrates the percentile values of each EJ Indexes for a user specified 268.96 sq. miles area of the city of Columbus. For the environmental variable traffic proximity and volume, the city is at the $90^{\text {th }}$ percentile in the state, which implies that only 10 percent of the state population has a higher block group value that the average person in the city being analyzed. 


\section{Macrothink}

Environmental Management and Sustainable Development

ISSN 2164-7682

2017, Vol. 6, No. 1

\section{EJ Index for PM2.5}

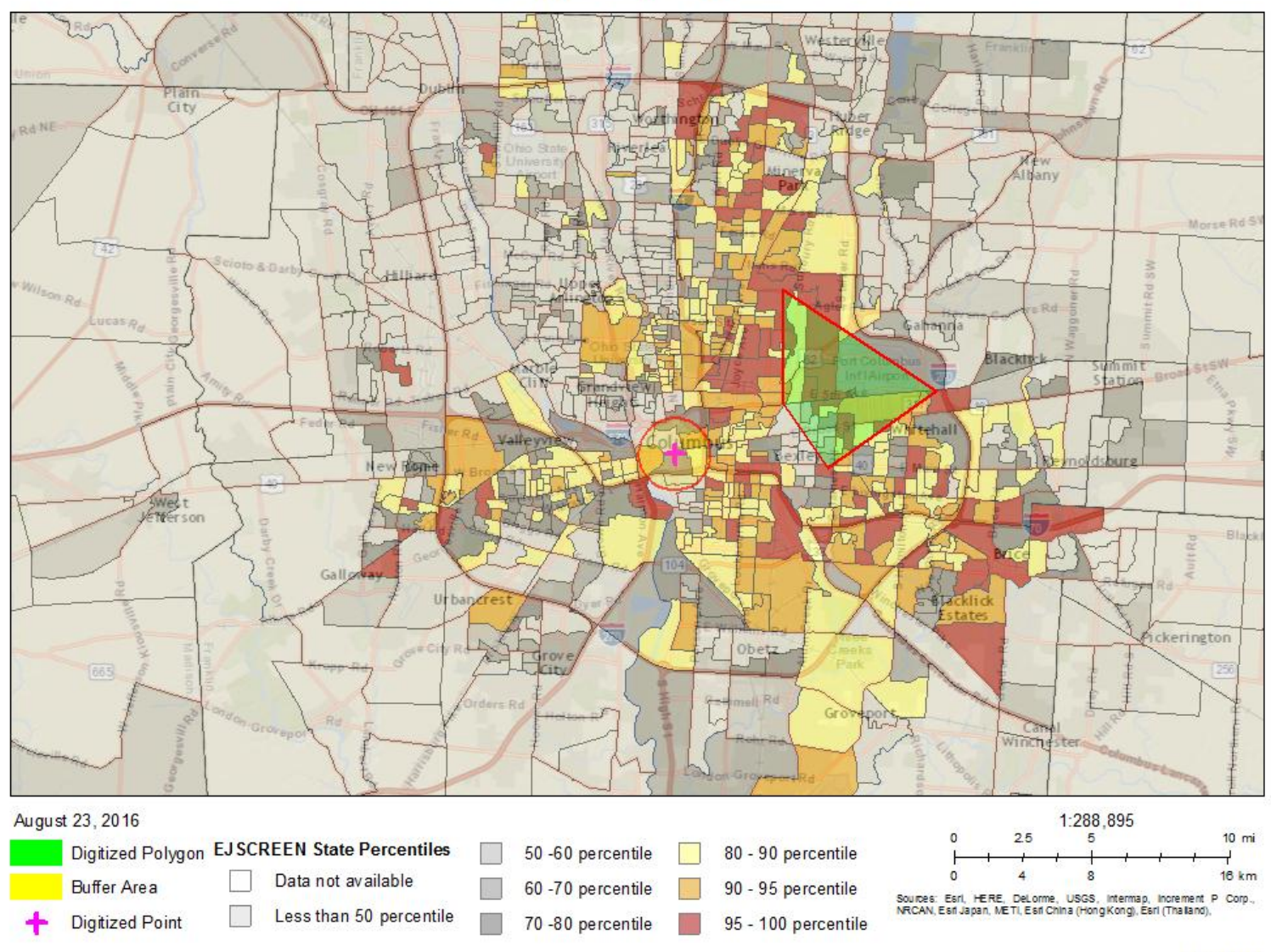

Figure 2. Map of census blocks indicating EJ Index for PM 2.5 for the city of Columbus, Ohio

Table 1. EJ Index for twelve environmental variables for the city of Columbus

\begin{tabular}{|l|l|l|l|}
\hline Selected Variables & State Percentile & EPA Region Percentile & USA Percentile \\
\hline EJ Indexes & 79 & 76 & 62 \\
\hline EJ Index for PM2.5 & 79 & 76 & 62 \\
\hline EJ Index for Ozone & 80 & 78 & 67 \\
\hline EJ Index for NATA* Diesel PM & 77 & 62 \\
\hline EJ Index for NATA* Air Toxics Cancer Risk & 80 & 78 & 64 \\
\hline EJ Index for NATA* Respiratory Hazard Index & 80 & 86 & 76 \\
\hline EJ Index for Traffic Proximity and Volume & 90 & 78 & 72 \\
\hline EJ Index for Lead Paint Indicator & 81 & 85 & 76 \\
\hline EJ Index for Superfund Proximity & 90 & 80 & 71 \\
\hline EJ Index for RMP Proximity & 83 & 79 & 70 \\
\hline EJ Index for Hazardous Waste Proximity & 80 & 77 & 64 \\
\hline EJ Index for Water Discharger Proximity & 79 & & \\
\hline
\end{tabular}




\section{Macrothink}

\section{CalEnviroScreen}

CalEnviroScreen is a statewide environmental health screening tool that can be used to help identify California communities that are disproportionately burdened by multiple sources of pollution. The California Office of Environmental Health Hazzard Assessment (OEHHA) (Lawson and Manatt., 2013), has developed the tool jointly with the California Environmental Protection Agency (CalEPA). The tool is also intended to help state decision-makers prioritize resources to target grants, investments, cleanup efforts, and enforcement actions to California's most disadvantaged communities. In other words, this tool is intended on environmental justice principles and CalEPA's environmental justice mission. The map shows the CalEnviroScreen 2.0 score for each census tract in California. Census Tract (Michigan State University, 2016) is an area roughly equivalent to a neighborhood established by the Bureau of Census for analyzing populations. The CalEnviroScreen scores are calculated by combining the scores for nineteen individual indicators that make up CalEnviroScreen. These indicators relate to pollution exposures and population characteristics.

\subsection{CalEnviroScreen Score}

The CalEnviroScreen score is calculated from the pollution burden and population characteristics groups of indicators by multiplying the two scores. Since each group has a maximum score of 10, the maximum CalEnviroScreen Score is 100.

The mathematical formula for calculating scores uses multiplication.

$\begin{array}{llll}\text { Exposure \& } & * & \text { Population \& } & \text { CalEnviroScreen } \\ \text { Environmental Effects } & & \text { Socioeconomic Factors } & \text { Score }\end{array}$

Nineteen individual indicators can be grouped as pollution burden indicators and population characteristic indicators as shown in Figure 3.

\begin{tabular}{|l|l|}
\hline \multicolumn{1}{|c|}{ Exposure } & \multicolumn{1}{c|}{ Sensitive Populations } \\
Ozone & Age (Children and Elderly) \\
PM2.5 & Asthma Emergency Department Visits \\
Diesel Particulate Emission & Low Birth Weight Infants \\
Drinking Water Contaminants & Socioeconomic Factors \\
Pesticide Use & Low Education Attainment \\
Toxic Release from Facilities & Linguistic Isolation \\
Traffic Density & Poverty \\
Cleanup Sites & Unemployment \\
Groundwater Threats & \\
Hazardous Waste Sites and Facilities \\
Impaired Water Bodies \\
Solid Waste Sites and Facilities
\end{tabular}




\section{Macrothink}

\subsection{Pollution Burden Indicators}

Pollution burden scores for each census tract are derived (Rodriquez and Alexeeff, 2014) from the average percentiles of the seven exposure indicators and the five environmental effects indicators. Indicators from the environmental effects components were given half the weight of the indicators from the exposure component. The calculated average pollution burden score is divided by 10 and rounded to one decimal place for a pollution burden score ranging from $0.1-10$.

\subsection{Population Characteristics}

Population characteristics scores for each census tract are derived from the average percentiles for the three sensitive populations indicators and the three socioeconomic factors indicators. The calculated average percentile is then divided by 10 for a population characteristic score ranging from $0.1-10$.

\subsection{CalEnviroScreen Results}

CalEnviroScreen tool has census tract resolution. Figure 4 shows the CalEnviroScreen Scores for the state of California. Census tracts with darker red colors have the higher CalEnviroScreen scores and therefore have relatively high pollution burdens and population sensitivities. Census tracts with lighter green colors have lower scores, and correspondingly lower pollution burdens and sensitivities. Colors on these maps reflect the relative statewide scoring of individual census tracts.

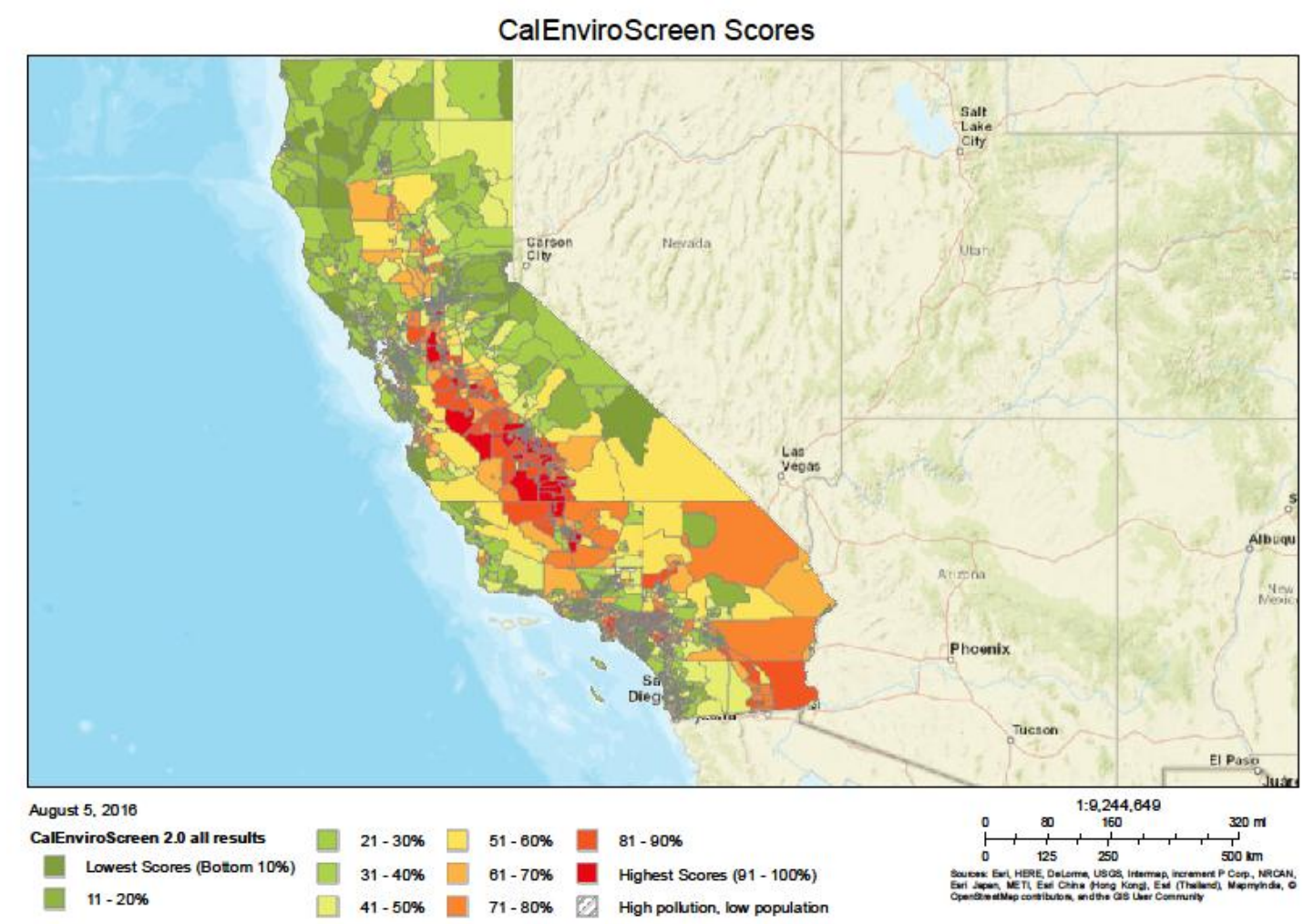

Figure 4. Map of census tracts indicating CalEnviroScreen Scores for the state of California 


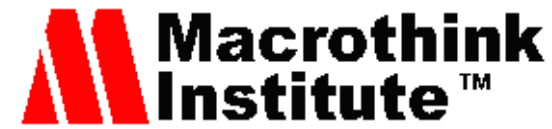

\section{EJ Atlas}

The EJ Atlas is a teaching, networking, and advocacy map that catalogs thousands of stories of resistance against damaging projects. Strategists, activist or organizers, scholars and teachers will find many uses for the database, as well as citizens wanting to learn more about the often-invisible conflicts taking place. EJ Atlas is an initiative of the Environmental Justice Organization, Liabilities, and Trade (EJOLT) project. The EJ Atlas is the global atlas of environmental justice, first launched on March 19, 2014.

EJ Atlas maps conflicts around the world across 10 main categories; nuclear, mineral ores \& building extractions, waste management, biomass \& land conflicts, fossil fuels \& climate justice, water management, infrastructure \& built environment, tourism recreation, biodiversity conservation conflicts and industrial \& utilities conflicts. The database contains information on the investors, the drivers for these deals, and their impact, basic data, the source of conflict, project details, conflict mobilization, impacts, and outcomes, references to legislation, academic research, videos, and pictures.

\subsection{EJ Atlas Results}

EJ Atlas documents and aggregates social conflicts on environmental issues around the world. Figure 5 shows the map of all the reported conflicts around the world under each conflict category. The user can either access or contribute data to the EJ Atlas. So far, 1842 cases were reported on EJ Atlas.

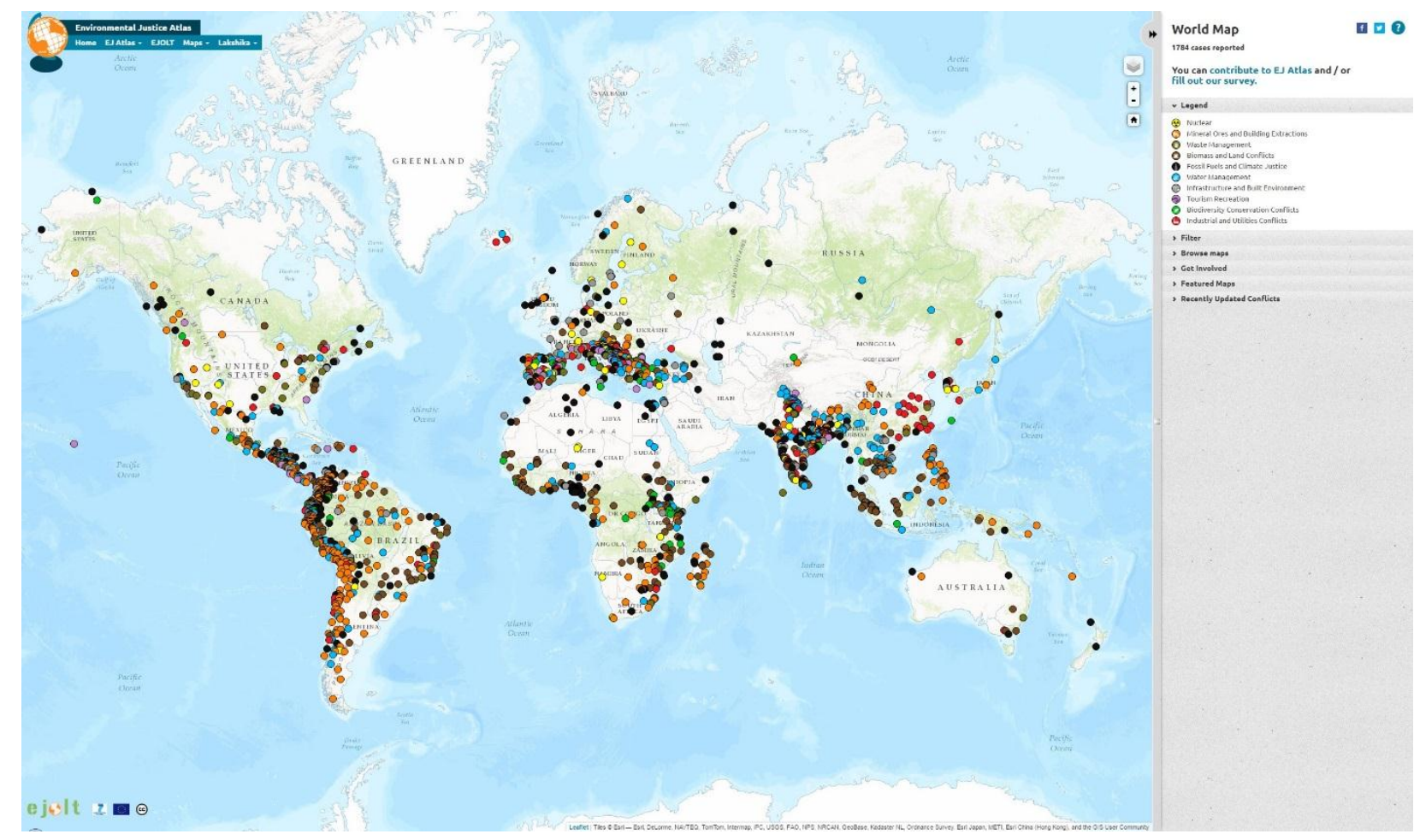

Figure 5. EJ Atlas world map with the reported conflicts around the world

Each reported case contains a comprehensive description of the conflict including the place, time, population type, environmental impacts, health impacts and socio-economic impacts of 


\section{Macrothink}

the projects. For an example, one of the most controversial projects in the world (Wood, J. R., 1993), Sardar Sarovar Dam (SSD) project, which has been built on the sacred Narmada river in Central India was reported on EJ Atlas. SSD is one of the most controversial dam projects because of the massive displacement it involves and because of the fraudulent measures are taken to impose it on the local population. People were left without proper compensation and rehabilitation. Due to the project; biodiversity loss, desertification, floods, groundwater pollution, reduced ecological connection, and soil erosion were visible environmental impacts. EJ Atlas has also listed social-economic impacts; violation of human rights, increase in violence and crime, loss of traditional knowledge and militarization visible because of this dam project. Landless peasants, ethnically and racially discriminated groups had organized public campaigns, street protests, and hunger strikes with the help of scientists, academic and city-based activist. However, the project is still in operation and the Indian government has taken over the project and rehabilitation measures have not been properly applied. The impacts on the people are already there. EJ Atlas consist hundreds of conflicting projects like these.

\section{Summary}

A summary of the comparison of three tools is illustrated in Table 1. The elements listed in the table (U.S. EPA, 2016) organize the summary of the comparison of the three major EJ tools in a much more efficient manner. The tools have some similar characteristics in generating maps and in selecting environmental variables. EJSCREEN mainly focus on combining demographic and environmental data to a selected locations and consider further evaluations. The output of EJSCREEN contains a much more detailed report than the other two and it can be used for further analysis and research for any area in the U.S... CalEnviroScreen maps environmental, health and socioeconomic data in the state of California and uses these for further review and policymaking. EJ Atlas aggregates social and environmental conflicts around the world and reports them with a full explanation. All three tools map the data where the user can easily find out the locations with potential risk. The tools have used data on air, land, and water quality, demographics and waste discharge in determining the EJ. 
Table 2. Three major EJ Tool Comparison Chart

\begin{tabular}{|c|c|c|c|}
\hline Elements & EJSCREEN & CalEniroScreen & EJAtlas \\
\hline Major Focus & $\begin{array}{l}\text { Screening and mapping } \\
\text { EJ Indexes and potential } \\
\text { risk areas based on } \\
\text { environmental and } \\
\text { demographic indicators } \\
\text { of a user specified } \\
\text { location }\end{array}$ & $\begin{array}{l}\text { Community mapping with } \\
\text { emphasis on } \\
\text { environmental, health and } \\
\text { socioeconomic data and } \\
\text { information resources. }\end{array}$ & $\begin{array}{ll}\text { Documents } & \text { and } \\
\text { catalogs social and } \\
\text { environmental } \\
\text { conflicts around the } \\
\text { world }\end{array}$ \\
\hline Output & $\begin{array}{l}\text { EJSCREEN standard } \\
\text { report with EJ Indexes } \\
\text { for each environmental } \\
\text { variable, a map } \\
\text { illustrating the EJ } \\
\text { Indexes for the selected } \\
\text { geographic location }\end{array}$ & $\begin{array}{l}\text { Issue profiles, maps, } \\
\text { community comparison } \\
\text { tables, links to additional } \\
\text { information and potential } \\
\text { solutions }\end{array}$ & $\begin{array}{l}\text { A world map } \\
\text { illustrating } \\
\text { environmental and } \\
\text { social conflicts }\end{array}$ \\
\hline \multicolumn{4}{|l|}{ Features } \\
\hline Maps & Yes & Yes & Yes \\
\hline $\begin{array}{l}\text { Geospatial Analysis } \\
\text { Tools }\end{array}$ & Yes & Yes & \\
\hline $\begin{array}{l}\text { Community } \\
\text { Comparison Tables }\end{array}$ & Yes & Yes & \\
\hline Screening Indices & Yes & Yes & Yes \\
\hline \multicolumn{4}{|l|}{ Data } \\
\hline $\begin{array}{l}\text { EPA Regulated Facility } \\
\text { Location }\end{array}$ & Yes & & \\
\hline Ecosystem Services & & & Yes \\
\hline Air Toxics & Yes & Yes & Yes \\
\hline $\mathrm{PM}$ and Ozone & Yes & Yes & Yes \\
\hline Water Quality & Yes & Yes & Yes \\
\hline Demographics & Yes & Yes & Yes \\
\hline Health-Based Output & Yes & & Yes \\
\hline \multicolumn{4}{|l|}{ Functionality } \\
\hline $\begin{array}{lr}\text { Add } & \text { Connecting } \\
\text { Technology } & \text { (Web } \\
\text { Services) } & \\
\end{array}$ & Yes & Yes & \\
\hline $\begin{array}{l}\text { Ability to Add Own } \\
\text { Data }\end{array}$ & Yes & & Yes \\
\hline $\begin{array}{l}\text { Ability to Download } \\
\text { Data }\end{array}$ & Yes & Yes & Yes \\
\hline
\end{tabular}




\section{Conclusion}

This paper compiles and compares three major EJ tools and their methodologies: EJSCREEN, CalEnviroScreen, and EJ Atlas. These tools help decision-makers and policy makers in different aspects. EJSCREEN introduces EJ Index, which is a combination of environmental indicators and demographic indicators for a selected location. The tool can be used for mapping and generate reports nationwide. In CalEnviroScreen, CalEnviroScreen score is based on the two indicators: pollution burden and population characteristics. CalEnviroScreen is mainly focused on $\mathrm{p}$ mapping the scores for the state of California. EJ Atlas maps and compiles social and environmental conflicts across the world where the user has the choice of either to access to contribute data. All these tools have different methodologies in representing Environmental Justice.

\section{Acknowledgement}

The study of EJ SCREEN was part of The University of Toledo Pollution Prevention Incentives for States (PPIS) Grant Program funded by the U.S. EPA. The opinions expressed in the paper are those of the authors. References in the papers to any specific commercial service or process, by trade name, trademark, manufacturer, or otherwise, do not necessarily imply their endorsement or recommendation by the U.S. EPA or the authors.

\section{Reference}

Asian Pacific Environmental Network. (2002). Environmental Justice and API Issues. Retrieved May 21, 2016, from http://archive.apen4ej.org/issues_what.htm

Bullard, R. D., \& Lewis, J. (1996). Environmental Justice and Communities of Color. Sierra Club Books: San Francisco, CA, USA.

Lawson, K. D., \& Manatt, P., (2013, August). Environmental Justice Comes of Age with New Science-Based Screening Tools. Retrieved May 18, 2016, from

http://www.environmentalleader.com/2013/08/20/environmental-justice-comes-of-age-with-n ew-science-based-screening-tools/

Michigan State University (2016). Finding Census Tract Data: About Census Tracts. Retrieved August 12, 2016, from http://libguides.lib.msu.edu/tracts

Rodriquez, M., \& Alexeeff, G. V. (2014, April)。 Draft California communities' environmental health screening tool, version 2.0. Retrieved June 2, 2016, from http://oehha.ca.gov/media/downloads/calenviroscreen/report/ces20publicreview04212014.pdf

Taylor, W. C., Floyd, M. F., Whitt-Glover, M. C., \& Brooks, J. (2007). Environmental justice: a framework for collaboration between the public health and parks and recreation fields to study disparities in physical activity. Journal of physical activity \& health, 4, S50.

https://doi.org/10.1123/jpah.4.s1.s50

The State of Maryland (2016). Environmental Justice in Maryland. Retrieved May 21, 2016, fromhttp://www.mde.state.md.us/programs/crossmedia/environmentaljustice/ejimplementatio ninmaryland/pages/programs/multimediaprograms/environmental_justice/implementation/det 
ails.aspx

U.S. Census Bureau (2011, July). What are census blocks? Retrieved July 18, 2016, from http://blogs.census.gov/2011/07/20/what-are-census-blocks/

U.S. Department of Agriculture (2012, March). Environmental Justice. Retrieved May 29, 2016, from http://www.nrcs.usda.gov/Internet/FSE_DOCUMENTS/stelprdb1187173.pdf

U.S. Environmental Protection Agency (2014). Overview and Demonstration of EJSCREEN: Environmental Justice Screening Tool. Retrieved May 6, 2016, from http://www.northeastarc.org/2014/documents/ppts/Introduction to EJSCREEN.pdf

U.S. Environmental Protection Agency (2015). Summary of Executive Order 12898 - Federal Actions to Address Environmental Justice in Minority Populations and Low-Income Populations. Retrieved July 18, 2016, from

https://www.epa.gov/laws-regulations/summary-executive-order-12898-federal-actions-addre ss-environmental-justice

U.S. Environmental Protection Agency (2016). Learn About Environmental Justice. Retrieved May 27, 2016, from

https://www.epa.gov/environmentaljustice/learn-about-environmental-justice

U.S. Environmental Protection Agency (2016, April). EPA 4-Tool Comparison Chart. Retrieved June 14, 2016, from https://www.epa.gov/ejscreen/epa-4-tool-comparison-chart

Wood, J. R. (1993). India's Narmada River Dams: Sardar Sarovar under Siege. Asian Survey, 33(10), 968-984. https://doi.org/10.2307/2645096

\section{Copyright Disclaimer}

Copyright for this article is retained by the author(s), with first publication rights granted to the journal.

This is an open-access article distributed under the terms and conditions of the Creative Commons Attribution license (http://creativecommons.org/licenses/by/3.0/). 